\title{
Pharmacokinetics and Pharmacodynamics of once-daily prolonged-release tacrolimus in liver transplant recipients
}

Running Title: Pharmacokinetics and Pharmacodynamics of once-daily prolonged-release tacrolimus

Marie Allard, PharmD 1,2,\#, Alicja Puszkiel, PharmD 1,3,\#, Filomena Conti, MD, PhD 4,5,6, Lucie Chevillard, PharmD, PhD 7,8, Nassim Kamar, MD, PhD 9,10, Gaëlle Noé, PharmD, PhD 1, Mélanie White-Koning, PhD ${ }^{3}$, Audrey Thomas-Schoemann, PharmD, PhD 1,2, Tabassome Simon, MD, PhD 5,11, Michel Vidal, PharmD, PhD 1,2, Yvon Calmus, MD, PhD 4,5,6, Benoit Blanchet, PharmD, PhD 1,2,*

\# These two authors contributed equally to this work

1 Département de Pharmacocinétique et Pharmacochimie, Hôpital Cochin, Assistance Publique - Hôpitaux de Paris, Paris, France

2 UMR8638 CNRS, UFR Pharmacie, Université Paris Descartes, PRES Sorbonne Paris Cité, France

${ }^{3}$ Cancer Research Center of Toulouse (CRCT), Inserm U1037, Université Paul Sabatier, Toulouse, France

${ }^{4}$ Unité Médicale de Transplantation Hépatique, Hôpital Pitié Salpêtrière, Assistance Publique

- Hôpitaux de Paris

${ }^{5}$ Sorbonne Université, UPMC Université Paris 06, France

${ }^{6}$ INSERM, UMR-S 938, Centre de Recherche Saint-Antoine, Paris, France

${ }^{7}$ INSERM, U1144, Paris, F-75006, France

8 Université Paris Descartes, UMR-S 1144, Paris, F-75006, France 
${ }^{9}$ Département de Néphrologie et de Transplantation, CHU Rangueil, Université Paul Sabatier, Toulouse, France

${ }^{10}$ INSERM U1043, IFR-BMT, Toulouse, France

${ }^{11}$ Département de Pharmacologie Clinique et Centre de Recherche Clinique de l'Est Parisien, Assistance Publique - Hôpitaux de Paris, Paris, France

\section{Email :}

Marie Allard : marie.allard3@gmail.com

Alicja Puszkiel : alicjapuszkiel@gmail.com

Filomena Conti : filomena.conti@aphp.fr

Lucie Chevillard : luciechevillard@gmail.com

Nassim Kamar : kamar.n@chu-toulouse.fr

Gaelle Noe : gaelle.noe@aphp.fr

Melanie White-Koning : melanie.white-koning@univ-tlse3.fr

Audrey Thomas-Schoemann : audrey.thomas@aphp.fr

Tabassome Simon : tabassome.simon@aphp.fr

Michel Vidal : michel.vidal@aphp.fr

Yvon Calmus : yvon.calmus@aphp.fr

* Corresponding author:

Benoit Blanchet, PharmD, PhD

Département de Pharmacocinétique et Pharmacochimie, Hôpital Cochin, Assistance Publique - Hôpitaux de Paris

27 rue Faubourg Saint Jacques, Paris, France

Phone number: 33158412313

benoit.blanchet@aphp.fr 
Funding: This study was funded by a grant from Astellas Pharma Europe. The sponsor was Assistance Publique - Hôpitaux de Paris (Clinical Research and Innovation Department). Astellas Pharma Europe provided financial support to conduct this clinical trial.

Conflicts of interest: The authors have indicated that they have no conflicts of interest regarding the content of this article

Contribution: Conceptualization, FC, YC, BB; Investigation: MA, AP, FC, GN, NK, AT, MV, YC, BB; data analysis: MA, AP, LC, BB, MWK; project administration: TS; Roles/Writing - original draft: AP, LC, YC, BB; Writing - review and editing: MWK, MA, AP, FC, LC, GN, NK, AT, TS, MV, YC, BB. 


\section{Abstract}

\section{Purpose}

3 There is limited published data regarding the pharmacokinetics (PK) and pharmacodynamics

4 (PD) of prolonged-release tacrolimus (PRT) after liver transplant. We aimed to compare PK and PD of PRT in early and stable liver transplant recipients by developing a population PK model of PRT and investigating the profile of calcineurin activity (CNA) in the peripheral blood mononuclear cells.

\section{Methods}

A conversion from twice-daily immediate-release tacrolimus (IRT) to once-daily PRT based on one-to-one daily dose was performed at day 7 (D7) and D90 post-transplantation in groups $\mathrm{A}(n=12)$ and $\mathrm{B}(n=12)$, respectively. Extensive PK samplings including whole blood tacrolimus (TAC) concentration and CNA assessment were performed at D14 and D104 in groups $A$ and $B$, respectively. TAC concentration-time data $(n=221)$ were analyzed using non-linear mixed effects modeling.

\section{Findings}

A two-compartment model with linear elimination and a delayed first order absorption characterized by two transit compartments best described PK data. Model-predicted dosenormalized $(6.0 \mathrm{mg} / \mathrm{day})$ area under the TAC concentration-time curve over the dosing interval $\left(A \cup C_{T A C}\right)$ in groups $A$ and $B$ were similar (geometric mean $235.6 \mathrm{ng} / \mathrm{mL} . \mathrm{h}$ [CI95\% = 139.6 - 598.7] vs $224.6 \mathrm{ng} / \mathrm{mL}$.h [117.6 - 421.5], respectively, $p=0.94)$. Area under the CNA versus time curve over the dosing interval $\left(A \cup C_{C N A}\right)$ were not different between both groups (4897 \pm 3437 and $4079 \pm 1008 \mathrm{pmol} / \mathrm{min} / 10^{6}$ cells, respectively, $p=0.50$ ). In group A, trough CNA at D14 post-transplantation was statistically higher than that measured just before the switch to PRT (i.e D7 post-transplantation) (198 \pm 92 vs $124 \pm 72 \mathrm{pmol} / \mathrm{min} / 10^{6}$ cells, $n=8$, respectively, $p=0.048$ ), while no statistical difference in TAC concentration was observed ( $p$ $=0.11$ ). In group B, no statistical difference between D90 and D104 was observed in either trough CNA (149 \pm 78 vs $172 \pm 82 \mathrm{pmol} / \mathrm{min} / 10^{6}$ cells, respectively, $n=6, p=0.18$ ) or TAC concentration $(p=0.17)$. No graft rejection was observed in either of the groups. 


\section{Implications}

2 This study suggests that one-to-one dosage conversion to once-daily PRT during the early 3 post-transplantation period could result in significant CNA variations but without causing 4 graft rejection. Further investigations in larger cohorts are warranted to confirm these 5 results.

6 Study registry identification number: ClinicalTrials.gov Registration identification $7 \quad$ NCT02105155

8

9 Keywords: liver transplantation; prolonged-release tacrolimus; pharmacokinetics;

10 calcineurin activity 


\section{Introduction}

2 Tacrolimus (TAC) is a key immunosuppressive agent for the prevention and treatment of 3 allograft rejection in liver transplantation ${ }^{1}$. TAC binds with high affinity to FK-binding protein $4 \quad 12^{2}$. The drug-receptor complex specifically and competitively binds to and inhibits calcineurin, a calcium- and calmodulin-dependent phosphatase. This process inhibits the translocation of a family of transcription factors (NF-AT), leading to reduced transcriptional activation of cytokine genes such as interleukin (IL)-2 and thereby to a reduction of T-cell proliferation ${ }^{3}$. TAC has a narrow therapeutic range and a significant between-subject variability (BSV), and thus a close monitoring of whole blood trough concentrations is required to avoid under- or over-exposure ${ }^{4}$. Hence, therapeutic drug monitoring of TAC in liver transplant recipients is the benchmark method in this indication ${ }^{1}$. However, some liver transplant recipients with sufficient exposure to TAC nonetheless experience graft rejection 5,6 , suggesting that whole blood trough concentration may not be the most appropriate surrogate marker of pharmacodynamics (PD) in these patients. Different approaches such as evaluation of TAC intracellular concentration in peripheral blood mononuclear cells (PBMC) ${ }^{7}$ or calcineurin activity (CNA) in PBMC ${ }^{6-9}$ could be helpful to overcome this issue in those patients. However, they are not currently used for the clinical management of liver transplant recipients in daily clinical practice. Liver transplant recipients are usually treated with twice-daily immediate-release tacrolimus (IRT) (Prograf $\left.{ }^{\circledR}\right)$. Non-adherence to treatment has been found to be a significant factor associated with graft rejection and graft loss ${ }^{10}$. A once-daily prolonged-release tacrolimus (PRT) (Advagraf ${ }^{\oplus}$ ) has been developed to improve treatment adherence. The phase III trial conducted in de novo liver transplant recipients showed that both efficacy and safety profiles were similar between twice-daily IRT and once-daily PRT ${ }^{11}$. The twice-daily dosage of IRT usually shifts to once-daily PRT based on a one-to-one conversion (i.e. same daily dose for IRT and PRT). The narrow therapeutic range and the significant BSV in the pharmacokinetics (PK) of TAC, could result in significant variations in PD in some patients, possibly leading to acute graft rejection within the early post-transplantation period. In this context, exploring both PK and PD of once-daily PRT at the time of conversion becomes mandatory. However, the PK data of once-daily PRT in liver transplant recipients are very sparse. A single population PK study was conducted to investigate once-daily PRT PK in 
1 stable liver transplant recipients ${ }^{12}$, while another study using a standard non2 compartmental approach characterized its PK during the early post-transplantation period $3{ }^{13}$. In this context, a population PK study including data from the early and late post4 transplantation period could be interesting to better characterize the PK/PD relationship of 5 once-daily PRT in liver transplant recipients. Finally, as far as we know, the profile of CNA has 6 not been investigated in PBMC from liver transplant recipients treated with once-daily PRT.

7 The aim of this study was to describe the PK of once-daily PRT using a population approach 8 and to characterize the CNA profile in PBMC in liver transplant recipients treated with once9 daily PRT and included in the CONVERSION ${ }^{\circledR}$ trial. 


\section{Patients and Methods}

\section{Study population and treatment}

The CONVERSION ${ }^{\circledR}$ trial (ClinicalTrials.gov Registration identification NCT02105155) is a prospective, randomized, multicenter trial aiming to prove the non-inferiority of the early conversion from IRT to PRT versus the conversion at three months after liver transplantation. Eligible patients (>18 years) underwent liver transplantation at day 1 (D1) and started treatment with IRT (Prograf ${ }^{\oplus}$ ). A conversion from IRT to PRT (Advagraf ${ }^{\oplus}$ ) was performed at D7 and D90 after transplantation in groups A and B, respectively (Figure 1). The dosage of twice-daily IRT shifted to once-daily PRT based on a one-to-one conversion (i.e same daily dose for IRT and PRT). After conversion, daily dosing was adjusted according to TAC whole blood trough concentration with a therapeutic range of $6-10 \mathrm{ng} / \mathrm{mL}{ }^{1}$. All patients provided written informed consent. The protocol was approved by the Committee for the Protection of Persons and the French National Agency for Medicines and Health Products Safety.

Two hundred and fifty liver transplant recipients were supposed to be included in the CONVERSION $^{\circledR}$ trial, and 40 of them in the PK/PD study ( $n=20$ in each group). However, only 90 patients were included in the CONVERSION ${ }^{\circledR}$ trial because of numerous simultaneous clinical trials. Furthermore, many patients refused to participate in the PK/PD study because of the lack of personal gain. In this context, PK and PD data come from 24 patients included in the CONVERSION ${ }^{\circledR}$ trial.

\section{PK data collection}

Extensive PK sampling was performed at D14 post-transplantation (i.e. at D7 postconversion) in group A and at D104 post-transplantation (i.e. at D14 post-conversion) in group B (Figure 1). Blood samples $(7 \mathrm{~mL}$ ) were drawn before next administration (at trough), $0.33,0.66,1,2,3,4,6,8$ and 24 hours after drug intake. Blood samples were also collected right before next drug intake (trough concentration) at D5, D7, D14, D30, D90 and D180 post-transplantation in group A and at D90, D104 and D180 post-transplantation in group B (Figure 1). Whole blood TAC concentrations were assayed using an ECLIA method ${ }^{14}$ on Cobas 8000 (Roche Diagnostics, Meylan, France). The calibration range of the ECLIA method was $1-40 \mathrm{ng} / \mathrm{mL}$ with a limit of detection of $0.5 \mathrm{ng} / \mathrm{mL}$. The intermediate precision and 
1 accuracy of the ECLIA method were below $8.1 \%$ and $5.1 \%$, respectively, at three levels of concentrations $(2.5,10.4 \text { and } 19.8 \mathrm{ng} / \mathrm{mL})^{14}$. The accuracy of our method was ensured by our participation in the TAC Proficiency Testing Scheme provided by the Cardiac and Vascular Sciences Analytic Unit of St. George's Hospital Medical School (D. Holt, London, United Kingdom).

At each follow-up visit, body composition and biological parameters were collected: body weight (BW), lean body mass (LBM), hematocrit (HT), glomerular filtration rate (GFR) estimated by Cockcroft-Gault formula, alanine aminotransferase (ALT), aspartate aminotransferase (AST), albumin (ALB), bilirubin (BIL). LBM was estimated according to the McLeay et al. formula ${ }^{15}$.

\section{Calcineurin activity in PBMC}

Trough CNA in PBMC (just before drug intake) was assayed immediately before the switch to PRT (i.e. at D7 and D90 post-transplant for groups A and B, respectively, Figure 1). Furthermore, CNA was assayed on the blood samples from extensive PK sampling (D14 for group A and D104 for group B) before next administration (at trough), 0.33, 0.66, 1, 2, 3, 4, 6, 8 and 24 hours after drug intake. For each blood sample, PBMC isolation was performed within 24 hours after blood collection ${ }^{16}$. First, granulocyte depletion was performed to prevent the influence of granulocytes on CNA ${ }^{17}$. For this purpose, the RosettSep ${ }^{\circledR}$ kit was used according to the manufacturer's instructions (StemCell Technologies, Grenoble, France). Second, PBMC were isolated by Ficoll density-gradient centrifugation (Unisep Ficolltubes, Abcys, Jerusalem, Israel), then washed and counted with Xn-9000 (Sysmex, Villepinte, France). Each sample including $10^{6} \mathrm{PBMC}$ was dried and frozen at $-80^{\circ} \mathrm{C}$ up to analysis. CNA assay was run in duplicate as previously described ${ }^{16}$. Briefly, PBMC lysates were incubated for 15 minutes at $30^{\circ} \mathrm{C}$ in analysis buffer including $50 \mathrm{mM}$ Tris- $\mathrm{HCl}, \mathrm{pH}$ 7.0, $0.1 \mathrm{M}$ Ethylene glycol-bis(2-aminoethylether)- $\mathrm{N}, \mathrm{N}, \mathrm{N}^{\prime}, \mathrm{N}^{\prime}$-tetraacetic acid (EGTA), $0.5 \mathrm{mM}$ dithiothreitol, 1 $\mathrm{mM} \mathrm{MnCl} 2,0.3 \mathrm{mg} / \mathrm{mL}$ bovine serum albumin, $0.1 \mathrm{mM} E G T A, 1 \mathrm{mM} \mathrm{CaCl} 2,0.1 \mu \mathrm{M}$ calmodulin and $500 \mathrm{nM}$ okadaic acid. The reaction was initiated by adding a 19 amino-acid phosphopeptide (DLDVPIPGRFDRRVSVAAE, Bachem, Voisin, France). Aliquots were sampled at 5 and 10 minutes. The reaction was stopped with $0.5 \%$ perchloric acid. Dephosphorylated

31 peptide concentrations were determined using high-performance liquid chromatography 
1 coupled with UV detection. The chromatography system consisted of Dionex Ultimate 300 equipped with a gradient pump with degas option and gradient mixer, a UV-visible detector, an autosampler, and a Chromeleon ${ }^{\circledR}$ chromatography workstation (Dionex Corporation, Sunnyvale, CA, USA). The within-day precision of this method was $13.3 \%$ including all the steps from blood collection to CNA assay ${ }^{16}$. CNA was expressed as picomole of formed dephosphorylated peptide per minute per $10^{6} \mathrm{PBMC}$ (pmol/min $/ 10^{6} \mathrm{cells}$ ).

\section{Non-compartmental Pharmacokinetic Analysis}

Whole blood concentrations of TAC from extensive PK sampling were used to calculate the area under the TAC concentration-time curve over the dosing interval ( $\left.A \cup C_{T A C}\right)$ using the trapezoidal rule.

\section{Population Pharmacokinetic Analysis}

TAC concentration-time data were analyzed by nonlinear mixed effects modeling using NONMEM $^{\circledR}$ software (version 7.4, ICON Development Solutions, Ellicott City, MD, USA) with Piraña ${ }^{\circledR}$ (version 2.9.7) and PsN toolkit (version 4.7.0). Analyses were carried out with first order conditional estimation method with interaction (FOCE-I). Data processing and plots were performed in $\mathrm{R}$ (version 3.4.2). Several structural models were used to fit the concentration-time data. First, one and two compartment models with first order absorption and elimination were tested. Since TAC was administered as a prolonged-release formulation, a first order process with either a lag time or transit compartments with an identical transfer rate constant $\left(\mathrm{k}_{\mathrm{tr}}\right)$ were tested to account for the delay in the absorption phase. The inclusion of BSV and between-occasion variability (BOV) defined as $\mathrm{OCC}_{1} \leq \mathrm{D} 28$ and $\mathrm{OCC}_{2}>\mathrm{D} 28$ for group $\mathrm{A}$ and $\mathrm{OCC}_{1} \leq \mathrm{D} 105$ and $\mathrm{OCC}_{2}>\mathrm{D} 105$ for group $\mathrm{B}$ was tested on all PK parameters according to an exponential model:

$$
\theta_{i}=\theta_{\mu} \cdot \exp \left(\eta_{i}+\eta_{1 i} \mathrm{OCC}_{1}+\eta_{2 i} \mathrm{OCC}_{2}\right)
$$

where $\theta_{i}$ is the estimate of the parameter for the $i$ th subject, $\theta_{\mu}$ is the population mean estimate of the PK parameter, $\eta_{i}$ is the deviation from the mean for the ith subject with zero mean and variance $\omega^{2}, \eta_{1 i}$ and $\eta_{2 i}$ is the deviation from the mean for the first $\left(\mathrm{OCC}_{1}\right)$ and second $\left(\mathrm{OCC}_{2}\right)$ occasion for the ith subject, respectively. Correlation between $\eta$ of PK parameters was tested using a $\omega$ block structure. The residual unexplained variability was 
1 function value (OFV $=-2$ loglikelihood), using the likelihood ratio test to test for significant

2 differences in goodness-of-fit (GOF) between nested models. A drop of at least 3.84 ( $\chi^{2}$ test, $3 \alpha=5 \%$, degree of freedom $=1$ ) between hierarchical models was considered statistically 4 significant. Additionally, the plausibility of parameter estimates with their precision (expressed by relative standard error, \%RSE), $\eta$-shrinkage value and model stability were considered.

\section{Covariate analysis}

The individual parameter estimates of the base model were used to investigate the correlations with biological and demographic variables. The following covariates were tested for their influence on clearance $(\mathrm{CL})$ : age, sex ( 0 for male and 1 for female), BW, LBM, HT, GFR, AST, ALT, ALB, BIL and study group (GRP). As PK data come from a large time period, different values of a covariate for the same patient were included in the data. Continuous covariates were tested according to the linear function:

$$
C L=\theta_{C L} \times\left(1+\theta_{\operatorname{cov}} \times\left(\operatorname{cov}-\operatorname{cov}_{\text {mean }}\right)\right)
$$

where $\theta_{C L}$ is the typical value of $C L$ in the population, cov is the individual covariate value, $\operatorname{cov}_{\text {mean }}$ is the mean value of a covariate in the studied population, $\theta_{c o v}$ is the fractional change in $\mathrm{CL}$ from the mean value of the covariate. Categorical covariates (sex, study group) were tested according to the following equation:

$$
C L=\theta_{C L} \times \theta_{c o v}{ }^{c o v}
$$

where $\theta_{\text {cov }}$ is the estimated influential factor for a covariate and cov is 1 or 0 . In the forward procedure, covariates were tested one by one and a covariate was considered significantly associated with a PK parameter if its inclusion resulted in a drop in OFV of at least 3.84 points ( $\chi^{2}$ test, $\left.\alpha=5 \%, d f=1\right)$. In the backward procedure, a full covariate model including the covariates significant in the forward procedure was built. A covariate remained in the final model if its removal resulted in an increase of at least 6.63 points $\left(\chi^{2}\right.$ test, $\alpha=1 \%, d f=$ 1) compared to the full covariate model.

\section{Model evaluation}

Diagnostic plots including population predictions (PRED) versus observed concentrations (DV), individual predictions (IPRED) versus DV, conditional weighted residuals (CWRES) 
1 versus PRED and time after dose were generated. Since patients were treated with different doses of TAC, the model validation was performed with a prediction-corrected visual predictive check ( $p c V P C$ ) based on 1000 replicates of the original data set and presented as concentrations versus time after dose and stratified on study group to facilitate interpretation. Finally, 500 bootstrap analyses with resampling using the final model were performed.

\section{Analysis of the individual PK parameters}

The individual $C L$ values obtained in NONMEM were used to calculate $A U C_{T A C}$ according to the following formula in the model input file:

$$
A \cup C_{i j}=D O S E_{i} \times F / C L_{i j}
$$

11 where $A U C_{i j}$ is the area under the concentration-time curve over the dosing interval for the $i$ th subject and $j$ th occasion, $D O S E_{i}$ is the administered dose for the ith subject, $C L_{i j}$ is the individual clearance value for the ith subject and $j$ th occasion and $F$ is the oral bioavailability of TAC (fixed in the model to 0.23 based on the literature) ${ }^{18}$.

\section{Statistical Analysis}

The demographic and biological characteristics of the study cohort are presented as median [interquartile range]. PK data are expressed as geometric mean [95\% confidence interval, $\mathrm{Cl} 95 \%]$ and PD data are expressed as mean \pm SD. The individual $A U C_{T A C}$ values obtained by non-compartmental analysis and population approach were normalized by the median daily dose which was administered prior to extensive PK sampling. Individual $A U C_{T A C}$ obtained in the non-compartmental analysis were compared with model-predicted $A U C_{T A C}$ for group $A$ and $B$ using non-parametric Wilcoxon paired sample test. $A \cup C_{T A C}$ obtained by both noncompartmental analysis and population approach were compared between group $A$ and $B$ using a Wilcoxon unpaired samples test. Since the number of patients per each study group is low, the ratio of the geometric means of $A \cup C_{T A C}$ group $A$ over $A \cup C_{T A C}$ group $B$ as well as its $\mathrm{Cl} 90 \%$ was calculated in addition to the non-parametric statistical tests to compare $A U C_{T A C}$ between groups $A$ and $B$.

From data of extensive PK sampling, individual 24-hour area under the calcineurin activity versus time curve $\left(A \cup C_{C N A}\right)$ was calculated using the trapezoidal rule. Only PD data from 
1 extensive PK sampling were used to investigate the PK/PD relationship. The $A U C_{C N A}$ were 2 compared between groups $A$ and $B$ using a Wilcoxon unpaired samples test. The relationship 3 between $A \cup C_{T A C}$ and $A U C_{C N A}$ was tested using Spearman's correlation test. All tests were 4 two-sided, and they were considered significant when $p$-values were $<0.05$. Computations 5 were performed using R software and SAS V9 statistical package (SAS institute, Cary, NC, 6 USA). 


\section{Results}

\section{Patients and TAC concentrations}

3 The baseline demographic and biological characteristics of 24 patients $(n=12$ patients in

4 each group) included in the study are summarized in Table 1. Overall, 221 blood samples including those from therapeutic drug monitoring were available for the PK analysis. The median number of measurements per individual was 11 (range $1-13$ ). The sampling time was in the range $0.1-27 \mathrm{~h}$ after drug intake. Four patients who did not have extensive PK sampling ( $n=1$ in group A and $n=3$ in group B) withdrew their informed consent on the day of the analysis as they did not understand that a part of the study included several blood samples drawn throughout the day and required them to stay for a longer time in the medical department. For the remaining patients $(n=20)$, extensive PK sampling was performed at median 14 days (range 13 - 21) and 104 days (95 - 109) after transplantation in groups $A$ and $B$, respectively. Figure 2 presents TAC concentrations versus time after dose at D14 $(n=11)$ and D104 $(n=9)$ for groups A and B, respectively (data from extensive PK sampling only).

\section{Non-compartmental Pharmacokinetic Analysis}

$\mathrm{AUC}_{\mathrm{TAC}}$ values were calculated using trapezoidal rule for the 20 patients $(n=11$ and $n=9$ for groups A and B, respectively) for which extensive PK data were available. The absolute $A \cup C_{\text {TAC }}$ means obtained by the non-compartmental analysis were similar between groups $A$ and B $(251.3 \mathrm{ng} / \mathrm{mL} . \mathrm{h}[\mathrm{Cl} 95 \%=108.5-460.7]$ and $200.7 \mathrm{ng} / \mathrm{mL} . \mathrm{h}$ [Cl95\% = $126.0-302.2]$, respectively, $p=0.17$ ). At the time of extensive PK sampling, the median dose of PRT was $7.0 \mathrm{mg} /$ day and 5.0 $\mathrm{mg} /$ day in groups $A$ and $B$, respectively, whereas median dose was $6.0 \mathrm{mg} /$ day regardless of study group. The geometric means of dose-normalized $A U C_{T A C}(6.0 \mathrm{mg} /$ day) were similar in groups A and B $(234.5 \mathrm{ng} / \mathrm{ml} . \mathrm{h}[\mathrm{Cl} 95 \%=130.3-670.6]$ and $231.0 \mathrm{ng} / \mathrm{ml} . \mathrm{h}[\mathrm{Cl} 95 \%=120.2-$ 433.4], respectively). The ratio of the geometric means of $A \cup C_{T A C \text { group } A}$ over $A \cup C_{T A C \text { group } B}$ was $1.01[\mathrm{Cl} 90 \%=0.66-1.56]$ (Table 2). The dose-normalized $A_{U} U C_{T A C}$ obtained by noncompartmental analysis were not statistically different between groups $A$ and $B(p=0.77)$. 


\section{Population Pharmacokinetic Analysis}

2 TAC concentration-time data were described by a two-compartment model with linear 3 elimination and a delayed first order absorption characterized by two transit compartments with an identical $k_{t r}$. Addition of transit compartments to describe the absorption phase resulted in a significant improvement of the model fit: one transit compartment dropped OFV by 14 points and two transit compartments by 25 points compared to the model without delayed absorption. Further addition of a third transit compartment did not improve the model fit. The PK parameters of the final model were: $k_{t r}$, clearance $(C L)$, volume of distribution of the central compartment $\left(V_{c}\right)$, inter-compartmental clearance $(Q)$, volume of distribution of the peripheral compartment $\left(V_{p}\right)$. The bioavailability $(F)$ of TAC was fixed to the value previously reported in the literature $(F=0.23)^{18}$. Therefore, the PK parameters $\left(C L, V_{c}, Q, V_{p}\right)$ were reported as absolute values. BSV was included on $k_{t r}, C L$ and $Q$. BSV could not be reliably estimated on $V_{c}$ and $V_{p}$ and inclusion of BSV on $F$ did not improve the model fit, thus BSV was fixed to zero for these three parameters. The addition of covariance between $\eta$ of the PK parameters did not improve the model fit. Finally, inclusion of BOV on CL resulted in a drop of 86 points in OFV and decreased the residual variability from $27.8 \%$ to $19.8 \%$.

Covariate analysis

The covariate analysis was performed on $\mathrm{CL}$ only as $\eta_{\mathrm{ktr}}$ showed significant deviation from a normal distribution (Shapiro-Wilk test, $p=0.02$ ) and $\eta_{\mathrm{Q}}$ was associated with shrinkage of $35 \%$. The correlation plots between individual $\mathrm{CL}$ of $\mathrm{OCC}_{1}$ and $\mathrm{OCC}_{2}$ and continuous covariates are presented in Supplementary Figure 1. The lack of influence of sex and GRP on $\mathrm{CL}$ is presented in Supplementary Figure 2. In the forward analysis, none of the tested covariates was significantly associated with CL (Supplementary Table 1) thus the final model did not include covariates. The estimates of the final model with corresponding \%RSE are presented in Table 3.

Evaluation of the final model GOF plots depicted in Figure 3 show no major bias of the model based on IPRED vs DV plot whereas CWRES vS PRED and time after dose were homogeneously distributed around the zero line although a slight bias at higher PRED values was observed. The PcVPC showed that 
1 the $5^{\text {th }}, 95^{\text {th }}$ percentiles and the median of the simulated data are in good agreement with

2 the $5^{\text {th }}$ and $95^{\text {th }}$ percentiles and the median of the observed concentrations for both groups

3 A and B (Figure 4). Finally, the mean estimates of the PK parameters from 500 bootstrap

4 analyses are in accordance with those estimated using the original data set (Table 3).

\section{Analysis of individual PK parameters}

Model-predicted absolute $A \cup C_{\mathrm{TAC}}$ at extensive PK sampling (corresponding to $\mathrm{OCC}_{1}$ for both group $A$ and $B)$ was no statistically different between group $A$ and $B(252.4 \mathrm{ng} / \mathrm{mL}$.h [Cl95\% = $111.3-510.5$ ] vs $195.2 \mathrm{ng} / \mathrm{mL} . \mathrm{h}$ [CI95\% = $124.9-302.1$ ], respectively, $p=0.17, n=20)$. Table 2 presents model-predicted geometric means of $A U C_{T A C}$ normalized for a median dose of $6.0 \mathrm{mg} /$ day. Dose-normalized $A \cup C_{T A C}$ were not statistically different between groups $A$ and $B(235.6 \mathrm{ng} / \mathrm{mL} . \mathrm{h}[\mathrm{Cl} 95 \%=139.6-598.7]$ and $224.6 \mathrm{ng} / \mathrm{mL} . \mathrm{h}$ [CI95\% = $117.6-421.5]$ $\mathrm{ng} / \mathrm{mL} . h$, respectively, $p=0.94$ ) and the ratio of the geometric means of $\mathrm{AUC}_{\mathrm{TAC} \text { group } \mathrm{A}}$ over $A_{U} C_{T A C \text { group } B}$ was 1.05 [Cl90\% $\left.=0.70-1.57\right]$ (Table 2). Finally, the comparison of $A U C_{T A C}$ obtained either by non-compartmental analysis or by population approach showed that both values were similar ( $p=0.90$ and $p=0.25$ for groups $A$ and $B$, respectively) further validating our PK model.

\section{PRT pharmacodynamics}

Figure 5 presents individual CNA profile (log scale) over the dosing interval at D14 for group $\mathrm{A}(n=11)$ and $\mathrm{D} 104$ for group $\mathrm{B}(n=9)$. The $A \cup \mathrm{C}_{\mathrm{CNA}}$ means were not statistically different between groups A and B (4897 \pm 3437 and $4079 \pm 1008 \mathrm{pmol} / \mathrm{min} / 10^{6}$ cells, Wilcoxon unpaired t-test $p=0.50)$. However, a larger BSV in AUC CNA was observed in group A (70.2 vs $24.7 \%$ for groups $A$ and $B$, respectively). No relationship was found between $A \cup C_{C N A}$ and either model-predicted absolute $\mathrm{AUC}_{\mathrm{TAC}}$ (rho coefficient, $\rho=0.26,[\mathrm{Cl} 95 \%=-0.20 ; 0.63] ; p=$ 0.25; Figure 6) or TAC whole blood trough concentration (rho coefficient, $\rho=0.20$, [CI95\% $=$ $0.27 ; 0.59], p=0.39$ ). The mean trough CNA activity (just prior TAC intake) at D14 posttransplantation in group A was statistically higher than that measured just before the switch to PRT (i.e. D7 post-transplantation) (198 \pm 92 vs $124 \pm 72 \mathrm{pmol} / \mathrm{min} / 10^{6} \mathrm{cells}, n=8$, respectively; paired t-test, $p=0.048)$, while no statistical difference was observed for TAC whole blood trough concentration (6.9 \pm 2.3 vs $10.1 \pm 5.4 \mathrm{ng} / \mathrm{mL}$, respectively; paired t-test, $p=0.11$ ). Finally, no statistical difference between D90 and D104 was observed for either 
1 trough CNA (149 \pm 78 vs $172 \pm 82 \mathrm{pmol} / \mathrm{min} / 10^{6}$ cells, $n=6$; paired t-test, $p=0.18$ ) or TAC 2 whole blood trough concentration ( $8.8 \pm 4.6 \mathrm{vs} 5.9 \pm 2.1 \mathrm{ng} / \mathrm{mL}$, respectively; paired t-test, $p$ $3=0.17)$. Finally, no graft rejection was observed in either group. 


\section{Discussion}

2 PRT (Advagraf ${ }^{\circledR}$ ) is EMA-approved for use in the context of liver transplants. However, there is limited published data regarding the PK and PD of PRT in this indication. As far as we know, the present study is the first to assess the PK of PRT within the early and late posttransplantation periods using a population approach. Furthermore, it provides new insights about the profile of CNA in PBMC from liver transplant recipients treated with PRT. In the population PK analysis, blood concentration-time data of once-daily PRT were described by a two-compartment model with delayed absorption characterized by two transit compartments. This is consistent with a previous population PK study reported by Moes et al. in which a two-compartment model with three transit compartments was used to characterize the PK of once-daily PRT in 66 stable liver transplant recipients ${ }^{12}$. The mean estimate of $\mathrm{CL}$ in our analysis was $5.1 \mathrm{~L} / \mathrm{h}(\mathrm{BSV}=34.7 \%)$ which is close to the value reported by Moes et al. (4.77 L/h, BSV $=45.4 \%)$. The analysis of the demographic and biological covariates on $\mathrm{CL}$ did not allow us to identify any significant correlations. This may be due to small sample size and the small dispersion of the covariates in our study. Nevertheless, in stable liver transplant recipients treated with PRT, Moes et al. did not report any significant influence of the covariates which we tested on total $\mathrm{CL}^{12}$. It has been reported that the expression of $C Y P 3 A 5 * 1$, both in donor and receiver of a liver transplant, significantly increases $\mathrm{CL}$ of TAC in patients treated with PRT ${ }^{12}$. Other studies conducted in kidney transplant recipients treated with PRT also reported the influence of CYP3A5*1 on $\mathrm{CL}{ }^{19,20}$. We could not confirm or contradict these results because pharmacogenetic data were not available in our study. It was decided not to conduct an analysis of CYP3A5*1 genotype in the CONVERSION study because the frequency of CYP3A5*1 genotype in the French population is low $(13 \%)^{21}$ and as the study included a small number of patients, the statistical power would not have been sufficient to draw any firm conclusion. Similarly, using a mixture model in the PK population analysis to identify the subpopulation carrying the CYP3A5*1 allele would not have been possible. Regarding the genetic polymorphisms of drug transporters such as MDR1, although its influence on TAC PK has been reported, the results still remain controversial ${ }^{22}$. In the same way as for the 
1 genetic polymorphisms of drug transporters on TAC PK because of the lack of statistical 2 power.

3 To further evaluate the validity of our model, the individual $A U C_{T A C}$ obtained using a 4 population approach were compared with those obtained using a non-compartmental analysis with data from extensive PK sampling. $A U C_{T A C}$ means of groups $A$ and $B$ obtained using either a non-compartmental or a population approach were not statistically different ( $p=0.90$ and $p=0.25$ for groups $A$ and $B$, respectively). Furthermore, comparison of AUC TAC values obtained by both approaches showed no statistical differences between groups $A$ and B ( $p=0.77$ and $p=0.94$, respectively). Finally, the geometric means of model-predicted dose-normalized $A U C_{\text {TAC }}$ in our study $(235.6 \mathrm{ng} / \mathrm{mL} . \mathrm{h}[\mathrm{Cl} 95 \%=139.6-598.7]$ and 224.6 $\mathrm{ng} / \mathrm{mL} . \mathrm{h}[\mathrm{Cl} 195 \%=117.6-421.5]$ for groups $\mathrm{A}$ and $\mathrm{B}$, respectively, normalized to median dose of $6.0 \mathrm{mg} / \mathrm{day}$ ) are close to those previously reported in liver transplant recipients obtained using a non-compartmental approach ${ }^{23}$. Indeed, Florman et al. reported a mean AUC $_{\text {TAC }}$ of $184 \pm 63 \mathrm{ng} . \mathrm{h} / \mathrm{mL}$ at day 28 post-transplantation in liver transplant recipients treated with PRT (mean dose of $5.2 \mathrm{mg} /$ day). Taken together, these results suggest that the developed model satisfyingly describes the TAC concentration-time data. However, the limitation of our PK analysis is the small number of patients. Therefore, our results are not conclusive and need to be confirmed in larger cohorts. Moreover, some individual PK profiles in our study show a second peak of absorption. This was previously observed in liver and kidney transplant recipients treated with a different PRT formulation (Envarsus $\left.{ }^{\circledR}\right)^{24,25}$ and was described by a double-gamma absorption model. In our analysis, the attempts to describe the second absorption peak did not give a reliable estimation of the PK parameters probably due to an insufficient number of samples in the absorption phase or the fact that it was only observed in some patients. In addition, the low number of PK samples in the absorption and distribution phases might be the reason for high BSV on $\mathrm{k}_{\mathrm{tr}}$ and Q. Although we analyzed the PK data with a model which did not account for the second peak of absorption, the comparison of $\mathrm{AUC}_{\mathrm{TAC}}$ values obtained with the non-compartmental approach and predicted by the PK model were in good agreement for both study groups which shows that our model accurately described the data.

30 CNA is a surrogate marker of TAC PD. Different PK/PD studies conducted in liver transplant 31 recipients have suggested that assessment of CNA within the early post-transplantation period could be helpful to predict acute graft rejection in patients well exposed to TAC ${ }^{6,7}$. In 
1 the present study, no relationship was found between $A \cup C_{T A C}$ and $A U C_{C N A}$ values regardless

2 of the moment of conversion from IRT to PRT, as previously reported ${ }^{6-8}$. Different factors

3 such as the amount of cytosolic FKBP12 ${ }^{26}$ and FKBP13, FKBP51 acting as a reservoir ${ }^{2}$, the

4 genetic polymorphism of the calcineurin catalytic subunit $\alpha^{27,28}$ and the etiology of liver disease before transplant ${ }^{29}$ might significantly influence the CNA in PBMC regardless of the whole blood TAC concentration. Besides, Lemaitre et al. showed that CNA in PBMC was not further associated to intracellular concentration of TAC in liver transplant recipients ${ }^{7}$, which supports our result. The BSV in $\mathrm{AUC}_{\mathrm{CNA}}$ for group $\mathrm{A}$ is in accordance with that reported at D7 and D14 post-transplantation in liver transplant recipients treated with twice-daily IRT ${ }^{6-8}$. However, it was 3-fold higher compared to the BSV in $\mathrm{AUC}_{\mathrm{CNA}}$ for group B (70.2 vs $24.7 \%$, respectively) while $A \cup C_{C N A}$ means were not statistically different in both groups. In addition, absolute $A \cup C_{T A C}$ values were similar between groups $A$ and $B(p=0.17)$ which altogether suggests that factors other than drug exposure contribute to this variability. Although patients' characteristics regarding immunophilins (FKBP12, 13 and 51) were probably different between both groups, the magnitude of immune response during the early posttransplantation period might also contribute to the large BSV in $A \cup C_{C N A}$. Besides, our study shows that the conversion from IRT to PRT in a 1:1 ratio based on total $\mathrm{mg} /$ day dose could also contribute to this variability. Interestingly, trough CNA at D14 in group A was statistically higher than that measured just before the switch to PRT ( $p=0.048)$, while no difference in TAC whole blood trough concentration was observed. Furthermore, neither trough CNA nor TAC whole blood trough concentration at D90 and D104 was different in group B. Finally, no graft rejection was observed in our PK/PD study regardless of study group. Although the number of patients was limited, these results suggest that the conversion from IRT to PRT during the early post-transplantation period could modify PD profile of calcineurin without causing graft rejection. Further investigations with a larger cohort of patients should be conducted to confirm this result. In conclusion, we have developed a population PK model for PRT in order to evaluate the PK/PD relationship for TAC in early and stable liver transplant recipients. The results suggest that one-to-one dosage conversion from twice-daily IRT to once-daily PRT during the early post-transplantation period could modify CNA in PBMC which might not be related to TAC 31 PK. The advantage of our study is the PK and PD comparison between early and stable transplant recipients. Using both a non-compartmental analysis and a population approach, 
1 we showed that the mean $A \cup C_{T A C}$ values between group $A$ and $B$ were not statistically

2 significantly different. Therefore, the model we have developed can be used to predict TAC

3 whole blood concentrations in liver transplant recipients under the same conditions and

4 dosing regimen as specified in our study. However, as the sample size in our study is low, our

5 results should first be confirmed in larger cohorts.

6

\section{Acknowledgments}

8 The authors are grateful to Dr Laurence Dubel (Astellas Pharma Europe) for her support in

9 the preparation of this clinical trial. The authors thank Juliette Polselli from the Clinical

10 Research Unit of East of Paris (URC-Est), Saint Antoine University Hospital (AP-HP) for study

11 coordination and logistics. 
2 1. European Association For The Study Of The Liver, European Organisation For Research And 3 Treatment Of Cancer. EASL-EORTC clinical practice guidelines: management of hepatocellular carcinoma. J Hepatol. 2012;56(4):908-943. doi:10.1016/j.jhep.2011.12.001

2. Bram RJ, Hung DT, Martin PK, Schreiber SL, Crabtree GR. Identification of the immunophilins capable of mediating inhibition of signal transduction by cyclosporin A and FK506: roles of calcineurin binding and cellular location. Mol Cell Biol. 1993;13(8):4760-4769.

83 3. Schreiber SL, Crabtree GR. The mechanism of action of cyclosporin A and FK506. Immunol 9 Today. 1992;13(4):136-142. doi:10.1016/0167-5699(92)90111-J

4. Wallemacq $\mathrm{P}$, Armstrong VW, Brunet $\mathrm{M}$, et al. Opportunities to optimize tacrolimus therapy in solid organ transplantation: report of the European consensus conference. Ther Drug Monit. 2009;31(2):139-152. doi:10.1097/FTD.0b013e318198d092

5. Capron A, Haufroid V, Wallemacq P. Intra-cellular immunosuppressive drugs monitoring: A

14 step forward towards better therapeutic efficacy after organ transplantation? Pharmacol Res. 2016;111:610-618. doi:10.1016/j.phrs.2016.07.027

16 6. Fukudo M, Yano I, Masuda S, et al. Pharmacodynamic analysis of tacrolimus and cyclosporine 17 in living-donor liver transplant patients. Clin Pharmacol Ther. 2005;78(2):168-181. 18 doi:10.1016/j.clpt.2005.04.008

19 7. Lemaitre $F$, Blanchet $B$, Latournerie $M$, et al. Pharmacokinetics and pharmacodynamics of 20 tacrolimus in liver transplant recipients: inside the white blood cells. Clin Biochem. 2015;48(6):40621 411. doi:10.1016/j.clinbiochem.2014.12.018

22 8. Blanchet B, Duvoux C, Costentin CE, et al. Pharmacokinetic-pharmacodynamic assessment of 23 tacrolimus in liver-transplant recipients during the early post-transplantation period. Ther Drug 24 Monit. 2008;30(4):412-418. doi:10.1097/FTD.0b013e318178e31b

25 9. Yano I, Masuda S, Egawa $\mathrm{H}$, et al. Significance of trough monitoring for tacrolimus blood concentration and calcineurin activity in adult patients undergoing primary living-donor liver transplantation. Eur J Clin Pharmacol. 2012;68(3):259-266. doi:10.1007/s00228-011-1129-x

10. Muduma G, Odeyemi I, Smith-Palmer J, Pollock RF. Budget impact of switching from an immediate-release to a prolonged-release formulation of tacrolimus in renal transplant recipients in

30 the UK based on differences in adherence. Patient Prefer Adherence. 2014;8:391-399. 31 doi:10.2147/PPA.S60213 
1 11. Trunečka $P$, Boillot $\mathrm{O}$, Seehofer $\mathrm{D}$, et al. Once-daily prolonged-release tacrolimus 2 (ADVAGRAF) versus twice-daily tacrolimus (PROGRAF) in liver transplantation. Am J Transplant. 3 2010;10(10):2313-2323. doi:10.1111/j.1600-6143.2010.03255.x

4 12. Moes DJ a. R, van der Bent S a. S, Swen JJ, et al. Population pharmacokinetics and 5 pharmacogenetics of once daily tacrolimus formulation in stable liver transplant recipients. Eur J Clin Pharmacol. 2016;72(2):163-174. doi:10.1007/s00228-015-1963-3

7 13. Ericzon B-G, Varo E, Trunečka $P$, et al. Pharmacokinetics of prolonged-release tacrolimus versus immediate-release tacrolimus in de novo liver transplantation: A randomized phase III substudy. Clin Transplant. 2017;31(6). doi:10.1111/ctr.12958 14. Shipkova $M$, Vogeser $M$, Ramos $P A$, et al. Multi-center analytical evaluation of a novel automated tacrolimus immunoassay. Clin Biochem. 2014;47(12):1069-1077. doi:10.1016/j.clinbiochem.2014.03.023 15. McLeay SC, Morrish GA, Kirkpatrick CMJ, Green B. The relationship between drug clearance and body size: systematic review and meta-analysis of the literature published from 2000 to 2007. Clin Pharmacokinet. 2012;51(5):319-330. doi:10.2165/11598930-000000000-00000 16. Blanchet B, Hulin A, Duvoux C, Astier A. Determination of serine/threonine protein 17 phosphatase type 2B PP2B in lymphocytes by HPLC. Anal Biochem. 2003;312(1):1-6. 17. Blanchet B, Hulin A, Ghaleh B, Giraudier S, Jouault H, Astier A. Distribution of calcineurin activity in blood cell fractions and impact of tacrolimus inhibition. Fundam Clin Pharmacol. 2006;20(2):137-144. doi:10.1111/j.1472-8206.2006.00399.x

18. Scholten EM, Cremers SCLM, Schoemaker RC, et al. AUC-guided dosing of tacrolimus prevents progressive systemic overexposure in renal transplant recipients. Kidney Int. 2005;67(6):2440-2447. doi:10.1111/j.1523-1755.2005.00352.x

24 19. Woillard J-B, de Winter BCM, Kamar N, Marquet P, Rostaing L, Rousseau A. Population 25 pharmacokinetic model and Bayesian estimator for two tacrolimus formulations--twice daily Prograf 26 and once daily Advagraf. $\mathrm{Br} J$ Clin Pharmacol. 2011;71(3):391-402. doi:10.1111/j.13652125.2010.03837.x 20. Benkali K, Rostaing L, Premaud A, et al. Population pharmacokinetics and Bayesian estimation of tacrolimus exposure in renal transplant recipients on a new once-daily formulation. Clin Pharmacokinet. 2010;49(10):683-692. doi:10.2165/11535950-000000000-00000 
1 21. Quaranta S, Chevalier D, Bourgarel-Rey V, et al. Identification by single-strand 2 conformational polymorphism analysis of known and new mutations of the CYP3A5 gene in a French 3 population. Toxicol Lett. 2006;164(2):177-184. doi:10.1016/j.toxlet.2005.12.007

4 22. Tron C, Lemaitre F, Verstuyft C, Petitcollin A, Verdier M-C, Bellissant E. Pharmacogenetics of 5 Membrane Transporters of Tacrolimus in Solid Organ Transplantation. Clin Pharmacokinet.

6 November 2018 nov 10. [epub ahead of print] doi:10.1007/s40262-018-0717-7

7 23. Florman S, Alloway R, Kalayoglu M, et al. Conversion of stable liver transplant recipients from

8 a twice-daily Prograf-based regimen to a once-daily modified release tacrolimus-based regimen.

9 Transplant Proc. 2005;37(2):1211-1213. doi:10.1016/j.transproceed.2004.11.086

10 24. Woillard J-B, Mourad M, Neely $M$, et al. Tacrolimus Updated Guidelines through popPK 11 Modeling: How to Benefit More from CYP3A Pre-emptive Genotyping Prior to Kidney Transplantation. Front Pharmacol. 2017;8:358. doi:10.3389/fphar.2017.00358 25. Woillard J-B, Debord J, Monchaud C, Saint-Marcoux F, Marquet P. Population Pharmacokinetics and Bayesian Estimators for Refined Dose Adjustment of a New Tacrolimus Formulation in Kidney and Liver Transplant Patients. Clin Pharmacokinet. 2017;56(12):1491-1498. doi:10.1007/s40262-017-0533-5 26. Kung L, Halloran PF. Immunophilins may limit calcineurin inhibition by cyclosporine and tacrolimus at high drug concentrations. Transplantation. 2000;70(2):327-335.

27. Noceti OM, Woillard J-B, Boumediene A, et al. Tacrolimus pharmacodynamics and pharmacogenetics along the calcineurin pathway in human lymphocytes. Clin Chem. 2014;60(10):1336-1345. doi:10.1373/clinchem.2014.223511

28. Noceti $\mathrm{O}$, Pouché $\mathrm{L}$, Esperón $\mathrm{P}$, et al. Activity of the Calcineurin Pathway in Patients on the Liver Transplantation Waiting List: Factors of Variability and Response to Tacrolimus Inhibition. Clin Chem. 2017;63(11):1734-1744. doi:10.1373/clinchem.2017.272534 29. Blanchet B, Hurtova M, Roudot-Thoraval F, et al. Deficiency in calcineurin activity in liver transplantation candidates with alcoholic cirrhosis or hepatocellular carcinoma. Liver Int. 2009;29(8):1152-1157. doi:10.1111/j.1478-3231.2009.02084.x 
Figure Legends

Figure 1. Design of the pharmacokinetic/pharmacodynamic study in the CONVERSION ${ }^{\circledR}$ trial. $^{\circ}$

Figure 2 Individual pharmacokinetic profiles of once-daily prolonged-release tacrolimus from extensive sampling day, corresponding to day 14 for group $A(n=11)$ and day 104 for group $\mathrm{B}(n=9)$.

Figure 3. Goodness-of-fit plots of the final model. (PRED, population predictions, IPRED, 10 individual predictions, DV, observed concentrations, CWRES, conditional weighted 11 residuals).

Figure 4. Prediction-corrected visual predictive check stratified on study group based on 1000 replicates of the original data set using the final model. Blue lines represent the 5 th and 95th percentiles of the observed concentrations, red line represents the median of the observed concentrations, blue areas represent 95\% confidence intervals around 5th and 95th percentiles of the simulated concentrations, red area represents $95 \%$ confidence interval around the median of the simulated concentrations and black points represent observed concentrations.

Figure 5. Individual CNA profile over the dosing interval at day 14 for group $A(n=11)$ and day 104 for group B $(n=9)$.

Figure 6. Relationship between area under the tacrolimus concentration-time curve over the dosing interval $\left(A \cup C_{T A C}\right)$ and 24-hour area under the calcineurin activity curve $\left(A \cup C_{C N A}\right)$ in liver transplant recipients treated with once-daily prolonged-release tacrolimus. Calcineurin activity (CNA) is expressed for $10^{6}$ cells. 


\section{Supplementary Material}

2

3 Supplementary Table 1 Results of the covariate analysis using the base model (forward 4 step).

5

6 Supplementary Figure 1 (a) Correlation plots between individual absolute clearance (CL) 7 obtained from the population approach and continuous covariates at the first 8 pharmacokinetic occasion $\left(\mathrm{OCC}_{1} \leq 28\right.$ days for group $\mathrm{A}$ and $\mathrm{OCC}_{1} \leq 105$ days for group $\left.\mathrm{B}\right)$; (b)

9 Correlation plots between individual absolute clearance $(\mathrm{CL})$ obtained from the population 10 approach and continuous covariates at the second pharmacokinetic occasion $\left(\mathrm{OCC}_{2}>28\right.$ 11 days for group $\mathrm{A}$ and $\mathrm{OCC}_{2}>105$ days for group B).

12

13 Supplementary Figure 2 Box-plots for individual absolute clearance (CL) obtained from the 14 population approach and categorical covariates. 


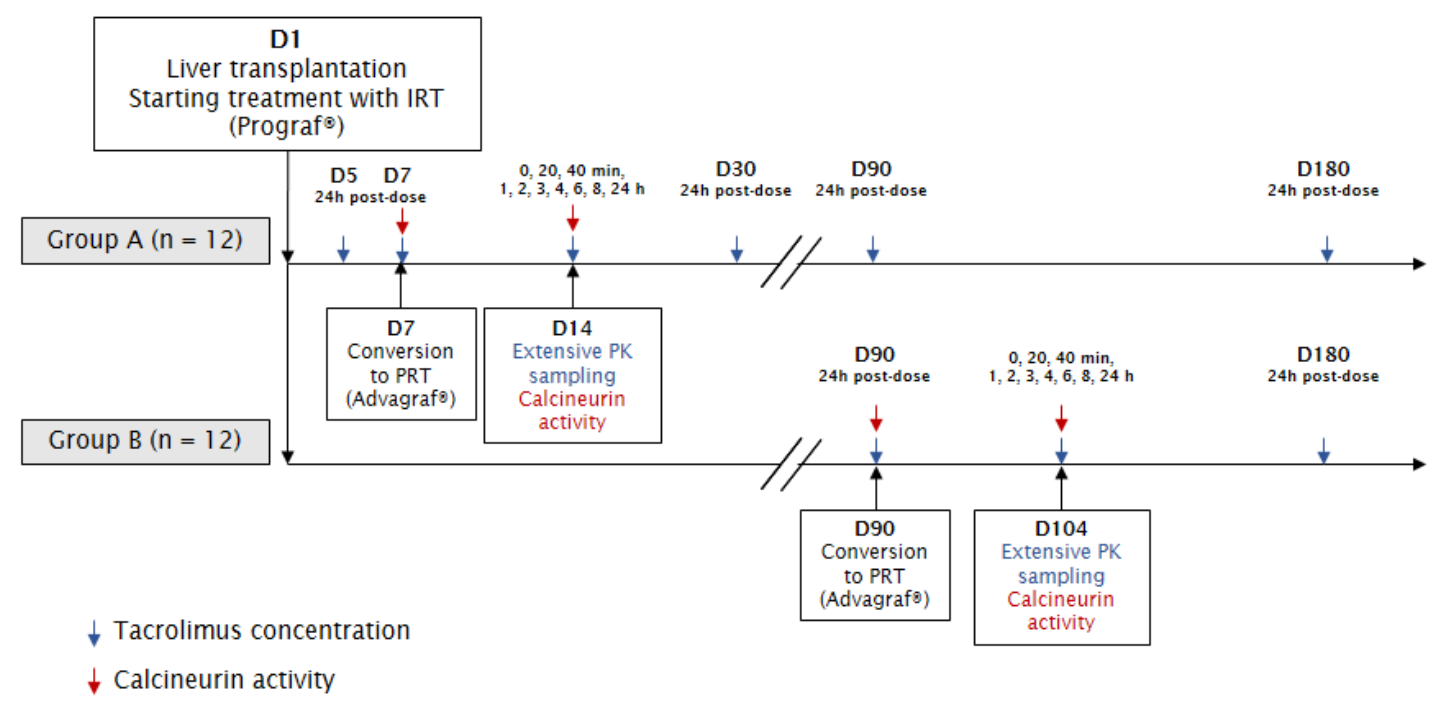




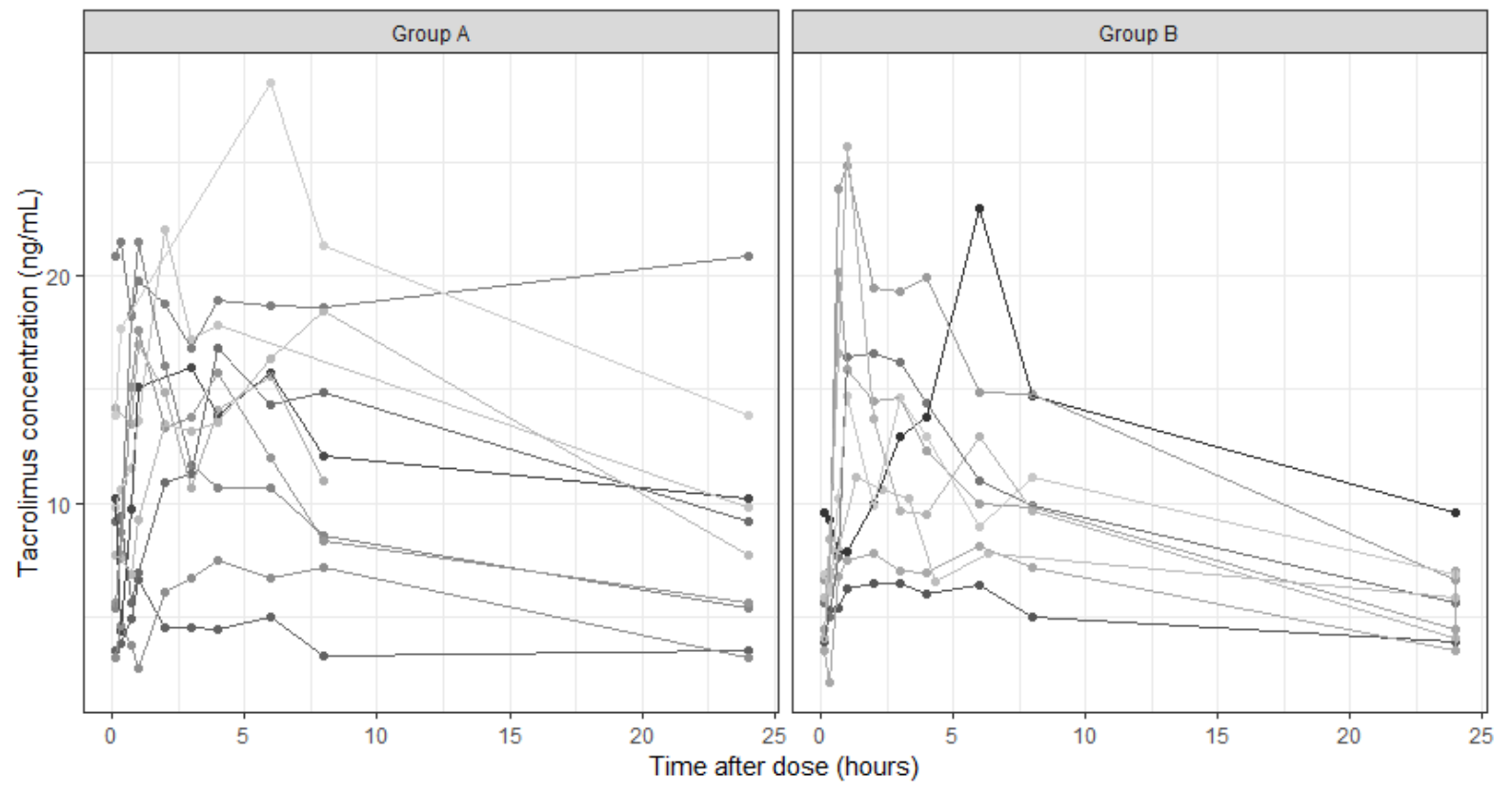



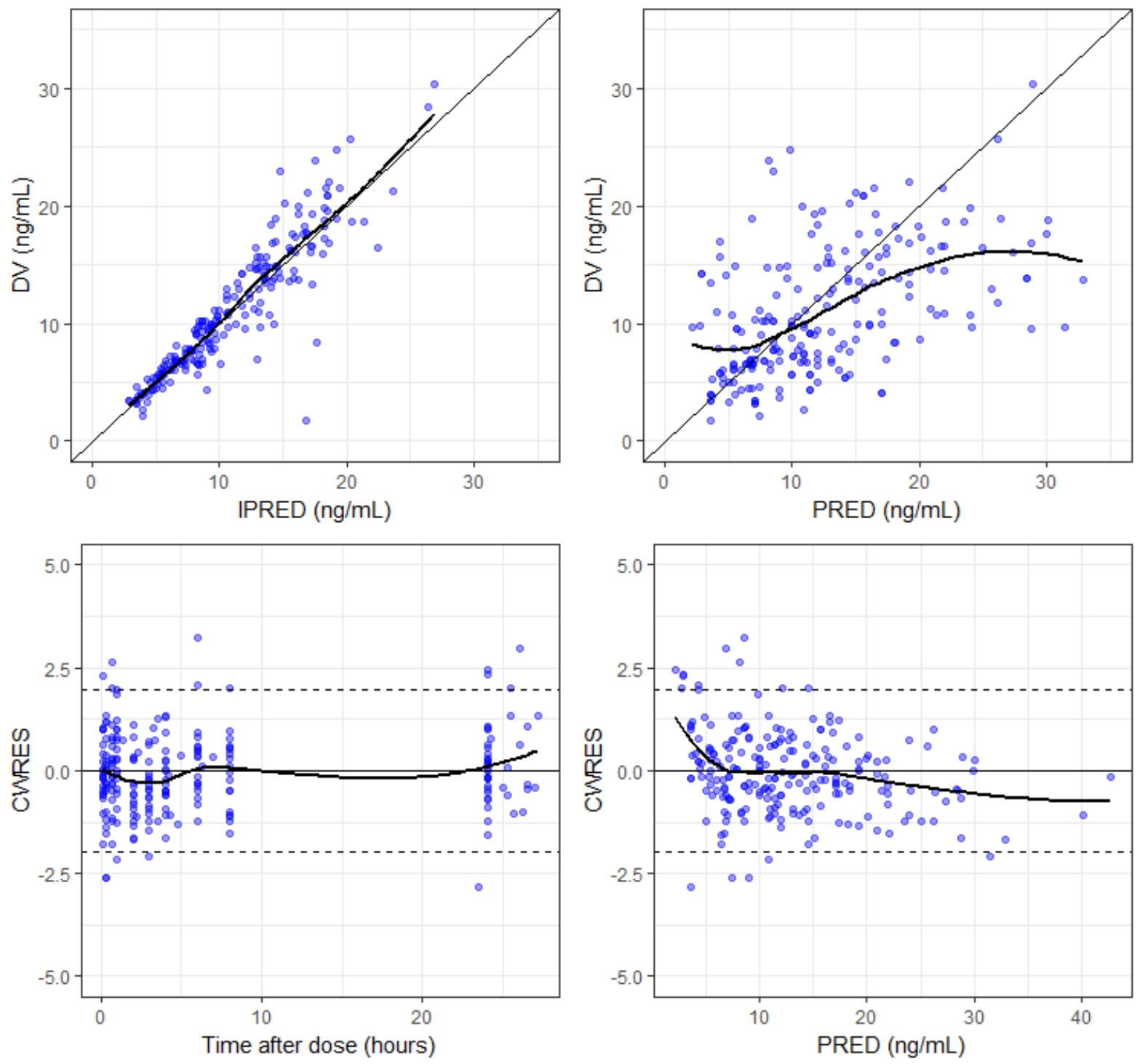


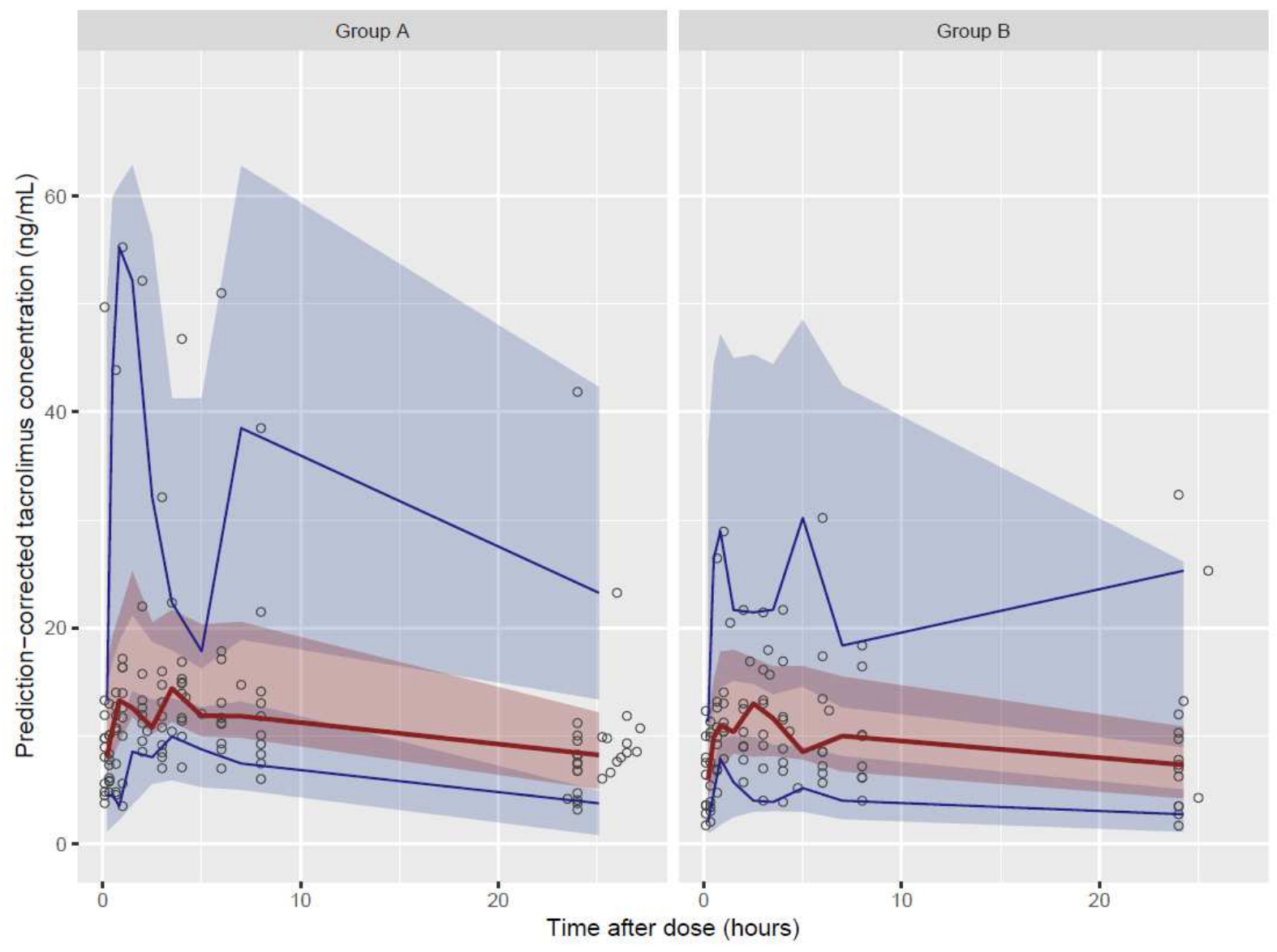




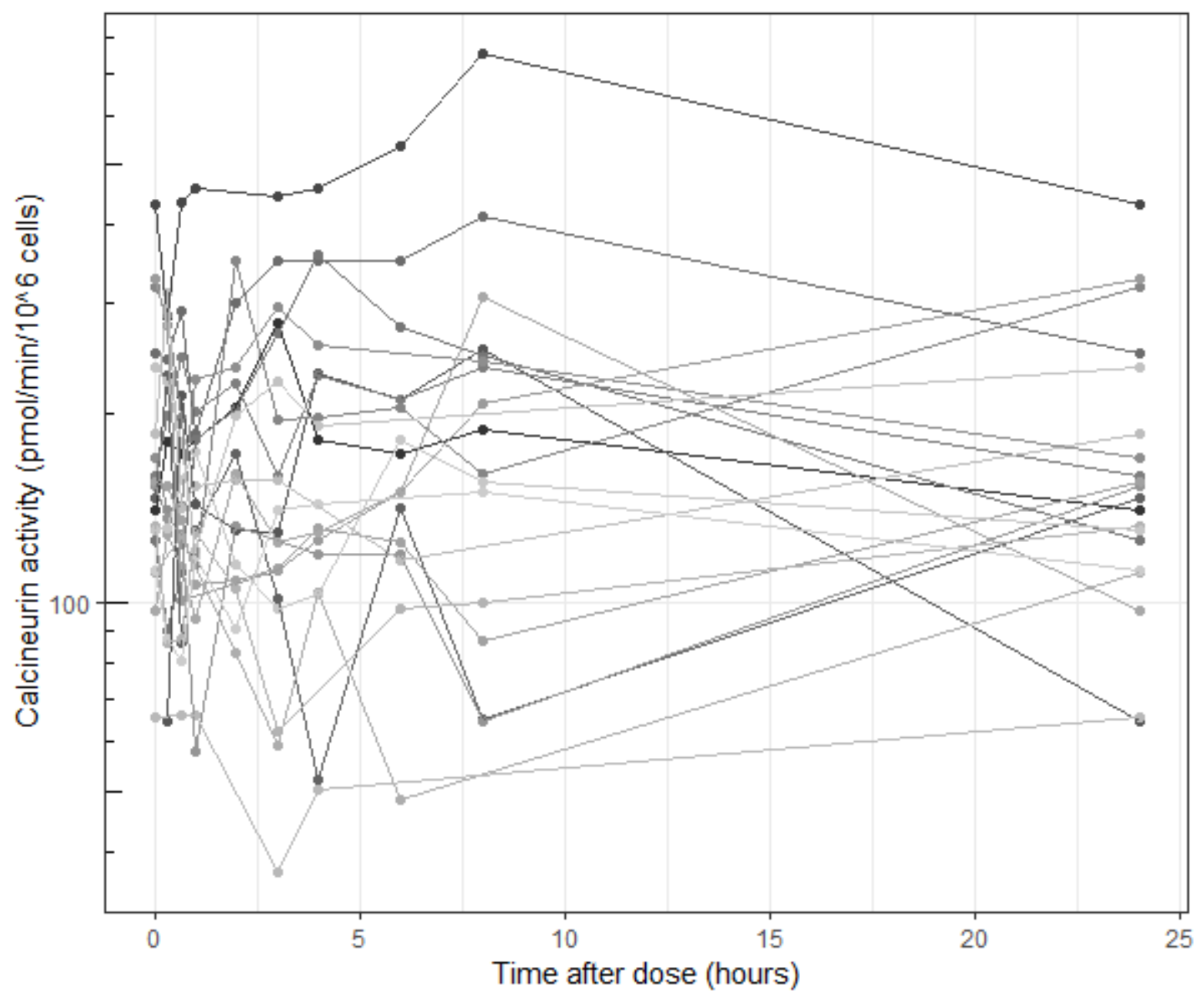




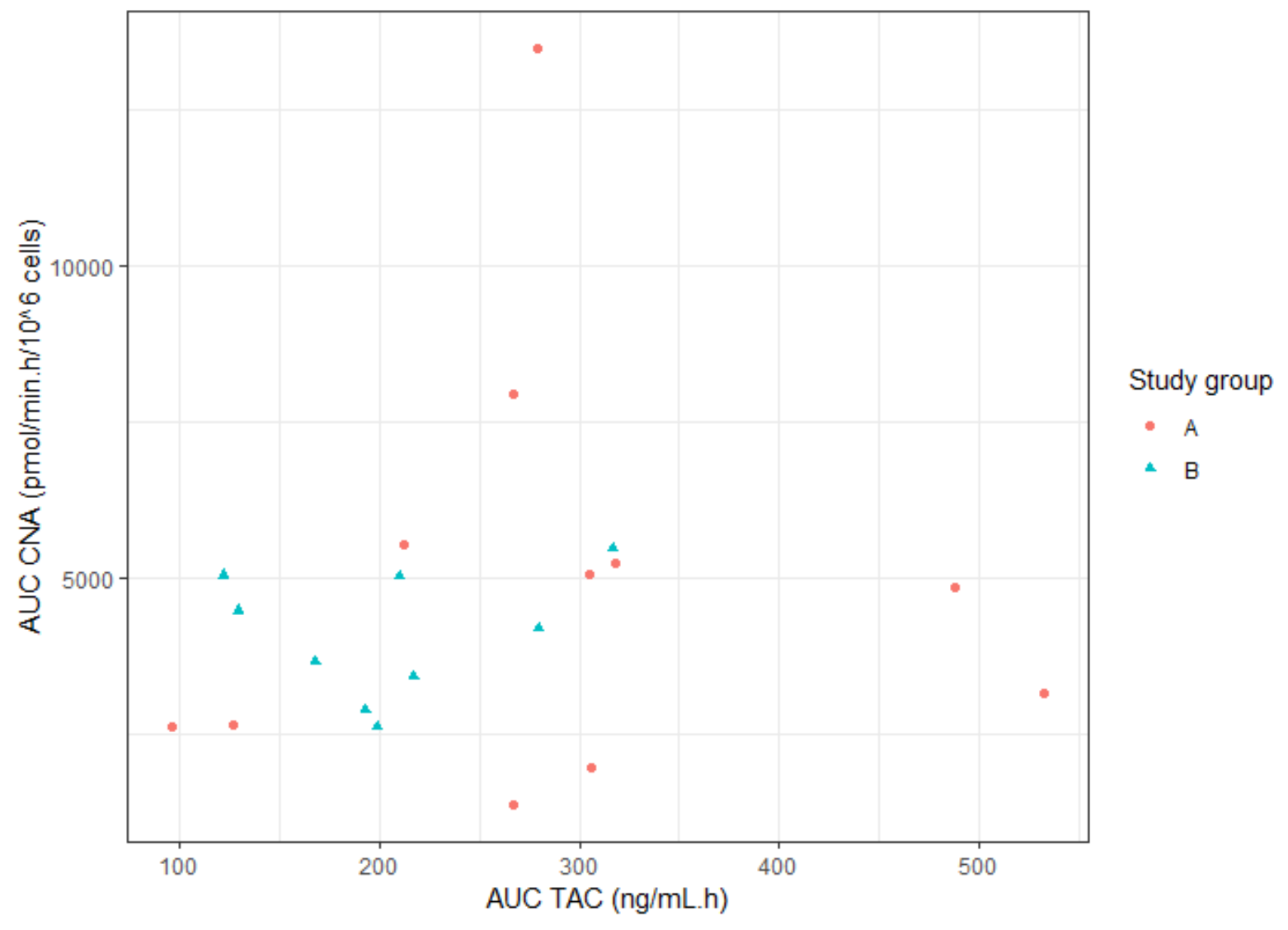


Table 1 Baseline demographic and biological characteristics of group A and B. Results are presented as median [interquatile] or median (range).

\begin{tabular}{|l|c|c|}
\hline & Group A $(n=12)$ & Group B $(n=12)$ \\
\hline Sex (female/male) & $3 / 9$ & $1 / 11$ \\
\hline Age (years) & $57[53-60]$ & $59[54-62]$ \\
\hline Body weight (kg) & $81[69-86]$ & $74.0[67-81]$ \\
\hline Lean body mass (kg) & $15[13-16]$ & $15[13-15]$ \\
\hline Biological data & & \\
\hline Hematocrit (\%) & $31[29-33]$ & $38[34-39]$ \\
\hline GFR (mL/min) & $105[70-117]$ & $82[54-91]$ \\
\hline AST (UI/L) & $43[16-69]$ & $21[17-25]$ \\
\hline ALT (UI/L) & $85[26-125]$ & $11[9-26]$ \\
\hline Albumin (g/L) & $30[28-34]$ & $40[36-47]$ \\
\hline Bilirubin ( $\mu$ mol/L) & $24[17-54]$ & $8.0[7-11]$ \\
\hline Tacrolimus therapy & & \\
\hline Median dose ${ }^{a}$ (mg/day) & $8.5 .[5.4-10.2]$ & $5.6 .[4.1-6.6]$ \\
\hline Trough concentration $(\mathrm{ng} / \mathrm{mL})^{\mathrm{a}}$ & & $5.0(2.5-12.0)$ \\
\hline AST, Aspartate & & \\
\hline
\end{tabular}

AST, Aspartate aminotransferase; ALT, Alanine aminotransferase; GFR, Glomerular filtration rate

${ }^{a}$ Median value at the time of extensive pharmacokinetic sampling 
Table 2 Comparison of $A \cup C_{T A C}$ obtained by non-compartmental analysis and population pharmacokinetic approach.

\begin{tabular}{|c|c|c|c|c|}
\hline & \multicolumn{2}{|c|}{$\begin{array}{c}\mathrm{AUC}_{\mathrm{TAC}}(\mathrm{ng} / \mathrm{mL} . \mathrm{h})^{\mathrm{a}} \\
\text { Geometric mean [Cl95\%] }\end{array}$} & \multirow[t]{2}{*}{$p$-value ${ }^{b}$} & \multirow{2}{*}{$\begin{array}{c}A \cup C_{\text {TAC Group A }} / \mathrm{AUC}_{\text {TAC Group B }} \\
\text { Ratio of geometric means }[\mathrm{Cl} 90 \%]\end{array}$} \\
\hline & Group A $(n=11)$ & Group B $(n=9)$ & & \\
\hline $\begin{array}{c}\text { Non- } \\
\text { compartmental }\end{array}$ & $\begin{array}{c}234.5 \\
{[130.3-670.6]}\end{array}$ & $\begin{array}{c}231.0 \\
{[120.2-433.4]}\end{array}$ & 0.77 & $\begin{array}{c}1.01 \\
{[0.66-1.56]}\end{array}$ \\
\hline $\begin{array}{l}\text { Model- } \\
\text { predicted }\end{array}$ & $\begin{array}{c}235.6 \\
{[139.6-598.7]} \\
\end{array}$ & $\begin{array}{c}224.6 \\
{[117.6-421.5]} \\
\end{array}$ & 0.94 & $\begin{array}{c}1.05 \\
{[0.70-1.57]} \\
\end{array}$ \\
\hline$p$-value ${ }^{c}$ & 0.90 & 0.25 & NA & NA \\
\hline
\end{tabular}

$\mathrm{Cl}$, confidence interval; $\mathrm{AUC}_{\mathrm{TAC}}$, area under the tacrolimus concentration-time curve over the dosing interval; NA, not available a Dose-normalized for median daily dose of $6.0 \mathrm{mg}$

${ }^{b}$ Wilcoxon unpaired test comparing non-compartmental and model-predicted AUC between group A and B

${ }^{c}$ Wilcoxon paired test comparing non-compartmental and model-predicted AUC for each study group 
Table 3 Mean pharmacokinetic parameter estimates obtained from the final model and from 500 bootstrap runs with resampling.

\begin{tabular}{|c|c|c|}
\hline Parameter & $\begin{array}{c}\text { Mean estimate (\%RSE) } \\
\text { [shrinkage] }\end{array}$ & $\begin{array}{l}\text { Bootstrap mean } \\
\qquad(95 \% \mathrm{Cl})\end{array}$ \\
\hline $\mathrm{k}_{\mathrm{tr}}\left(\mathrm{h}^{-1}\right)$ & 2.19 (19.7\%) & $2.14(1.37-2.92)$ \\
\hline $\mathrm{CL}(\mathrm{L} / \mathrm{h})$ & $5.09(8.2 \%)$ & $5.11(4.36-5.93)$ \\
\hline$V_{c}(L)$ & 93.5 (41.0\%) & $86.9(54.1-126)$ \\
\hline$Q(L / h)$ & 42.0 (46.2\%) & $43.1(20.2$ - 71.9) \\
\hline$V_{p}(L)$ & 135 (21.0\%) & $142(88.4$ - 196) \\
\hline$F($ fixed) & 0.23 & 0.23 \\
\hline \multicolumn{3}{|c|}{ Between-subject variability } \\
\hline $\mathrm{k}_{\mathrm{tr}}(\mathrm{CV} \%)$ & $94.5 \%$ (22.1\%) [13.3\%] & $80.6 \%(51.6-111)$ \\
\hline $\mathrm{CL}(\mathrm{CV} \%)$ & $34.7 \%$ (31.5\%) [26.1\%] & $33.8 \%(13.5-48.4)$ \\
\hline $\mathrm{Q}(\mathrm{CV} \%)$ & $151 \%(37.6 \%)$ [34.6\%] & $120 \%(67-170)$ \\
\hline \multicolumn{3}{|c|}{ Between-occasion variability ${ }^{a}$} \\
\hline CL (CV\%) & $39.8 \%(21.3 \%)$ & $36.2 \%(22.8-46.6)$ \\
\hline Proportional error (\%) & 19.8\% (8.6\%) [14.3\%] & $18.7 \%(16.0-21.1)$ \\
\hline
\end{tabular}

$\mathrm{Cl}$, confidence interval; $\mathrm{CL}$, clearance; $\mathrm{CV}$, coefficient of variation; $\mathrm{F}$, bioavailability; $\mathrm{k}_{\mathrm{tr}}$, tansfer rate constant between transit compartments; $Q$, inter-compartmental clearance; RSE, relative standard error; $V_{c}$, volume of distribution of the central compartment; $V_{p}$, volume of distribution of the peripheral compartment

a occasions (OCC) defined as: OCC1 <= 28 days and OCC2 > 28 days (group A); OCC1 <= 105 days and $\mathrm{OCC} 2>105$ days (group $\mathrm{B}$ ) 